\title{
Outdoor trapping and genetical characterization of populations of the webbing clothes moth Tineola bisselliella (Lepidoptera: Tineidae) in the broader area of Berlin
}

\begin{abstract}
Adapted and effective pest management strategies for the protection of irreplaceable culture heritage as well as for the prevention of damages in households and warehouses are based on reliable information about the presence and distribution of the pest organisms. Monitoring the webbing clothes moth Tineola bisselliella at thirteen outdoor stations in the broader area of Berlin give a first idea of their occurrence in an urban area and the hinterlands. The results demonstrate a seasonal abundance in the city and a missing of this species in the countryside. Data suggest a synanthropic occurrence of the webbing clothes moth rather than an invasion from natural reservoires. Possible molecular examinations on the species and subspecies level are presented to analyze the gene flow between populations and give an impression of species mobility as well as pathways of infestation.
\end{abstract}

Key words: infestation, monitoring, pheromone lures, synanthropy.

\section{INTRODUCTION}

The webbing clothes moth Tineola bisselliella is an economical important cosmopolitan pest. Their larvae feed on wool, feather, hair and pelt and effect damages in households, fabrics and on culture heritage (Kemper, 1935; Becker, 1960, Pinniger, 2010). The geographical origin is assumed to be in South Africa (Meyrick, 1927) from where the webbing clothes moth is immigrated with the developing global trade in the modern age. In Europe it was first mentioned in the $19^{\text {th }}$ century (Zeller, 1852). In the course of urbanization natural habitats are destroyed and a combination of physical factors is recreated (Weidner, 1958). Human homes with a balanced indoor climate, stored products and protection against environmental hazards offer a new diversity of food and habitats (Laibach, 1970). This situation provides niches with the opportunity for the colonization of invasive species from warmer clime with the ecological potential to survive and reproduce among dry conditions. T. bisselliella has a wide tolerance for abiotic environmental factors and its resistance to a relative humidity about $30 \%$ suggests a synanthropic occurrence (Griswold \& Crowell, 1936). Identifications of the webbing clothes moth in natural reservoires like bird nests are rare in the literature and do not indicate for a sustained colonization of such habitats in a moderate temperature 
zone (Plarre, 2009, Plarre \& Krüger-Carstensen, 2011). Although some nidicolous insect species of the keratinophagus guild are known as pest organisms in flats and warehouses an invasion of the webbing clothes moth from natural habitats seem to be improbable (Abraham \& Peters, 2008). Due to the little notion to fly of T. bisselliella, especially of the females, it is supposed that it can not overcome a distance about several meters with the exception of some cases or the utilization of favourable wind (Kemper, 1935; Weidner, 1970). In spite of numerous observations and monitoring studies of this pest organism the pathways of infestation remain obscure (Back, 1931; Child \& Pinniger, 1993, Brand \& Wudtke, 1997).

For the pest management today which is first concentrated on the prevention of pest outbreak, the success strongly depends on the localization of the origin of infestation. This paper shows results of an outdoor trapping of $T$. bisselliella in the broader area of Berlin and discusses the possible pathways of infestation.

\section{MATERIALS AND METHODS}

From the end of March 2010 up to November 2010 thirteen outdoor trapping locations in the broader area of Berlin were selected for a monitoring study of T. bisselliella (Fig. 1). Sticky traps with pheromone lures from the company Insect Limited Inc. (USA) were handed out to volunteers who put the traps on the balcony or in the

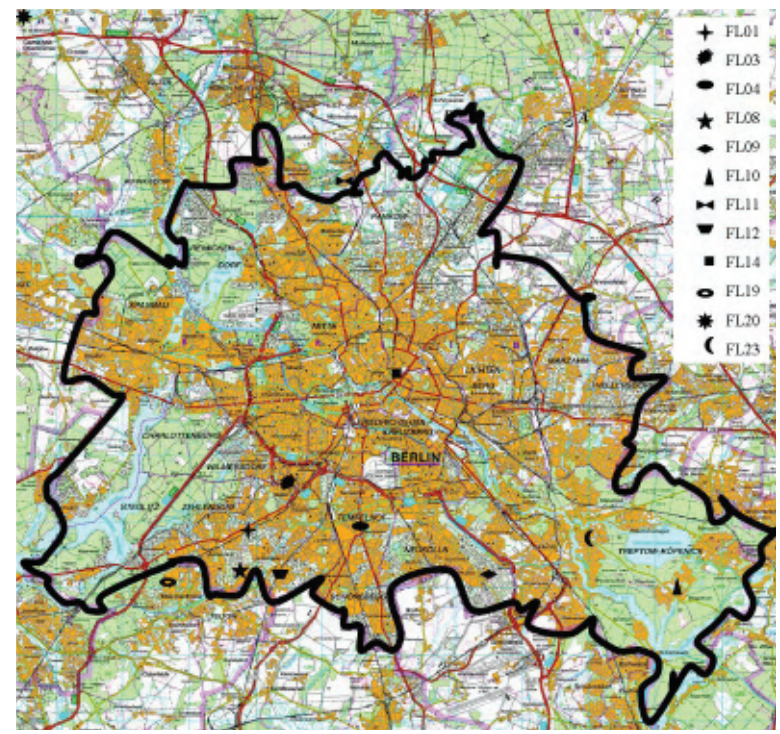

Fig. 1 - Twelve of the thirteen trapping locations (FL01 - FL23) in the broader area of Berlin (missing trapping location FL26 is situated in the north of Brandenburg and not included in this map). 
garden of their dwelling house. The lure, a polyethylene dispenser, contains a synthetic pheromone with the components of the sex pheromone of T. bisselliella. Both, lures and traps, were biweekly replaced and analyzed for the number of trapped organisms at each trapping location.

Since the pheromone lures only trap the males we also tested funnel traps filled with feather which were saturated with a 5\% yeast dilution and replaced them every fourth week. The contents of each trap were incubated at $27^{\circ} \mathrm{C}$ and $68 \%$ relative humidity and checked biweekly for moth eclosion.

\section{RESULTS}

The funnel traps did not contain any moths and no moth eclosed within five month after incubation at $27^{\circ} \mathrm{C}$ and $68 \%$ R.H. The results from the outdoor trapping with sticky traps containing pheromone lures indicate a seasonal abundance of $T$. bisselliella in the city of Berlin. Starting with the moth fly in the end of March the number of trapped webbing clothes moths increase up to the midyear and drop about the summer with single last catches in autumn, the begin of October (Fig. 2). In the hinterlands the number of trapped webbing clothes moths is low or absent and decrease with a growing distance to the city center (Fig. 3). The trapping locations in the city also show some larger or smaller differences in the number of trapped moths of $T$. bisselliella but the occurrence does not base upon the city center distance (Fig. 3) or the human population

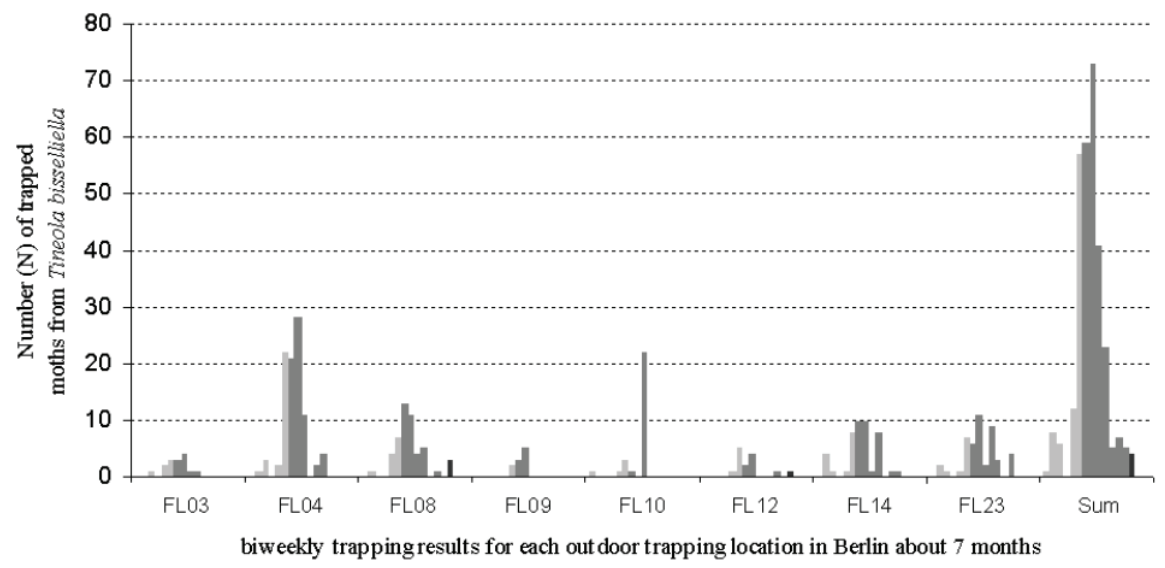

Fig. 2 - Biweekly results of a seven months outdoor trapping of $T$. bisselliella at eight trapping locations (FL03, FL04, FL08, FL09, FL10, FL12, FL14, FL23) in Berlin. The observation was done from the $26^{\text {th }}$ March up to the $5^{\text {th }}$ November 2010. 


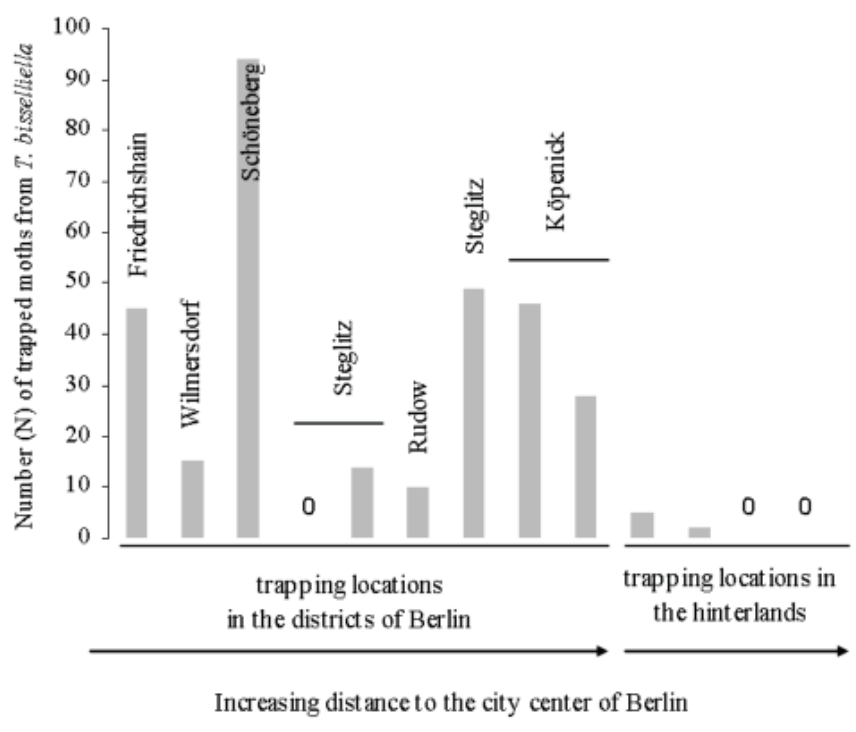

Fig. 3 - Trapping results over a period of seven months $(26.03-05.11 .2010)$ for each trapping location in several districts of Berlin and in the hinterlands. $(0=$ no trapped webbing clothes moth) with increasing distance to the city center of Berlin.

density (data not shown). Fig. 4 shows the results for each trapping locations separated into three groups concerning their disposition to the next dwelling house. Every balcony and terrace trap catches a different number of moths from $T$. bisselliella. Also, the traps in the gardens have different results of the number of trapped webbing clothes moths but their occurrence diminishes with prolonging distance of the trap to the next dwellings.

\section{DISCUSSION AND CONCLUSION}

This paper uses the well established monitoring method with pheromone lures for an outdoor trapping of $T$. bisselliella to get an impression of possible natural reservoirs and their appearance in our geographical area. Whereas Kemper (1935) suggests two generations with a fly period in the summer and autumn, the results from our first outdoor trapping of T. bisselliella in 2010 point out one generation per year, only (Fig. 2). A seasonal abundance with a presence during the warm season from April up to November and a disappearance during the coolest months, from December up to March, was observed in warehouses by Trematerra \& Fontana (1996), too. But they also detected responsiveness of the males during winter period if the temperature conditions were favourable. 


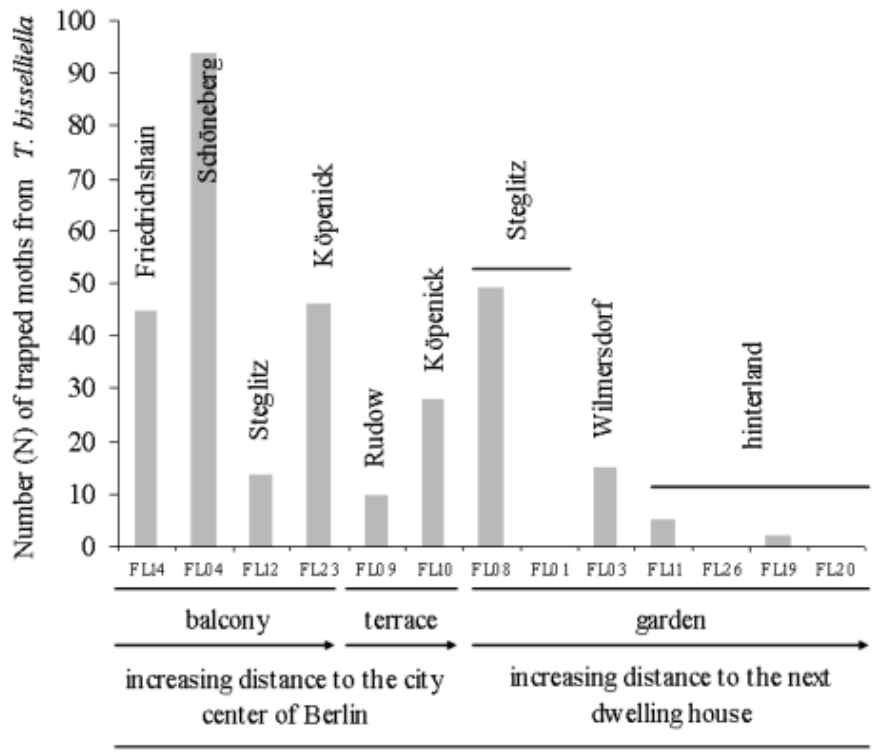

trapping locations in the broader area of Berlin

Fig. 4 - Trapping results over a period of seven months $(26.03-05.11 .2010)$ for each trapping location in the broader area of Berlin (FL14, FL04, FL12, FL23, FL09, FL10, FL08, FL01, FL03, FL11, FL26, FL19, FL20). Trapping locations are separated into three groups concerning their disposition to the dwellings.

The decreasing occurrence of the webbing clothes moth in the hinterlands compared to a higher number of trapped moths in the city leads to the question of their origin (Fig. 3). A high-density housing in urban areas like Berlin not only offers a higher probability for infestation around the trapping location than the countryside but also more beneficial climate due to the heat island effect (Frankie \& Ehler, 1978; Pickett et al., 2001; Kuttler, 2004). If we have a look on the number of trapped webbing clothes moths in the city (Fig. 4), differentiated into the traps on a balcony and terrace, the data fluctuated without any evident reason. But for the trapping locations in the gardens the catches decline with an increasing distance to the dwellings. Therefore, the occurrence of webbing clothes moths in natural habitats is more and more unlikely. If we take into account that the adults of this species rather stay inside of the infested material and fly only over a short distance, the origin of the trapped organisms should be close to the trapping location (Trematerra \& Fontana, 1996). Natural reservoirs like bird nest are availible in the city as well as in the countryside and if the webbing clothes moth is a nidicolous living insect, we should also find it in the countryside. But no funnel trap containing feathers mixed with yeast caught any webbing clothes moth in the hinter- 
lands although yeast odor is known to lure females ready for oviposition (Traynier et al., 1994).

If $T$. bisselliella represents an absolute synanthropic living insect and natural reservoirs are lacking, an infestation would mainly correlate with the dispersal of infested material and the population of each trapping location must then be distinguishable. A low mobility of populations is attended by the inhibition of the gene flow between them and become manifest in genetic differences over the time. Large genetic divergences with a minimal morphological change are possible and result in so-called "cryptic species" (Beebee \& Row, 2007). A powerful tool for studying population genetics is a mitochondrial genome (mtDNA) analysis. Because of its generally conserved gene complement and rapid rate of nucleotide substitution it provides an ideal system for comparative studies (Hu et al., 2009). Mainly the mtDNA control region is the most variable segment and has a large non-coding region containing controlling elements for replication and transcription (Boore, 1999).

The molecular analysis of the trapped webbing clothes moths as well as further examinations about the occurrence of T. bisselliella at the urban area and the hinterlands are the next steps to be carried out to get definite information about the pathways of infestation.

\section{REFERENCES}

Abraham R., Peters R. S., 2008 - Nistkästen als Lebensraum für Insekten, besonders Fliegen und ihre Schlupfwespen. Vogelwarte, 46: 195-205.

BACK E. A., 1931 - The control of moths in upholstered furniture. U. S. Department of Agriculture, Farmers' Bulletin, 1655.

BeCKer G., 1960 - Biologische Untersuchungen an Textilien. Handbuch der Werkstoffprüfung 2. Auflage Band 5, Thieme Verlag, Berlin/ Göttingen/ Heidelberg 971-1007.

BeeBee T., Row G., 2007 - An introduction to molecular ecology. Chapter 1. A history of molecular ecology. II. - Ed. Oxford University Press.

Boore J. L., 1999 - Animal mitochondrial genomes. Nucleic Acids Research, 27 (8): 1767-1780.

Brand, J., Wudtke, A., 1997 - Bekämpfung von Textilschädlingen mit Kohlenstoffdioxid. Restauro 4, Callwey Verlag.

Child R. E., Pinniger D. B., 1993 - Insect trapping in museums and historic houses. Proceedings of the First International Conference on Urban Pests, 1993.

Frankie G. W., Ehler L. E., 1978 - Ecology of Insects in Urban Environments. Ann. Rev. Entomol., 23: 367-387.

Griswold G. H., Crowell M. F., 1936 - The effect of humidity on the development of the webbing clothes moth, Tineola bisselliella. Ecology, 17: 241-250.

Hu L., Jianyu G., Haiyu L., Wanzhi C., 2009 - Progress in the Researches on Insect Mitochondrial Genome and Analysis of Gene Order. Science Foundation in China, 17 (2): 39-45.

KemPer H., 1935 - Die Pelz- und Textilschädlinge und ihre Bekämpfung; Hygienische Zoologie, Monographien zur Biologie und Bekämpfung der Gesundheits- und Wohnungsschädlinge. Band 7, Deutsche Gesellschaft für Kleintier- und Pelztierzucht GmbH \& Co, Leipzig: 69.

KuttLer W., 2004 - Stadtklima Teil 2: Phänomene und Wirkungen. Zeitschrift für Umweltchemie und Ökotoxikologie, 16 (4): 263-274. 
LAIBACH E., 1970 - Textilien - Nahrung und Unterschlupf für Insekten während des Transportes, im Lager und Haushalt. Zeitschrift für angewandte Entomologie, 65 (4): 431-435.

Meyrick E., 1927 - A revised handbook of British Lepidoptera. Watkins and Doncaster, London, UK.

Pickett S.T.A., Cadenasso M. L., Grove J. M., Nilon C. H., Pouyat R. V., Zipperer W. C., Constanza R., 2001 - Urban ecological systems: linking terrestrial ecological, physical, and socioeconomic components of metropolitan areas. Annu. Rev. Ecol. Syst., 32: 127-157.

Pinniger D., 2010 - Saving our heritage - Pest management in museums and historic houses. Outlooks on Pest Management, 21 (5): 239-241.

Plarre R., 2009 - Material- und Vorratsschädlinge, ihre Anpassung an den synanthropen Lebensraum sowie ihre wirtschaftliche Relevanz einschließlich ihrer Bekämpfung. Habilitationsschrift Fachbereich Biologie, Pharmazie, Chemie der Freien Universität Berlin.

Plarre R., Krüger-Carstensen B., 2011 - An attempt to reconstruct the natural and cultural history of the webbing clothes moth Tineola bisselliella (Lepidoptera: Tineidae). Journal of Entomological and Acarological Research, Ser. II, 43 (2): 83-93.

Traynier R. M. M., Schumacher R. K., Lau D. M., 1994 - Oviposition site selection by Tineola bisselliella, Tinea spp (Lepidoptera: Tineidae) and Anthrenus flavipes (Coleoptera: Dermestidae). Journal of Stored Products Research, 30 (4): 321-329.

Trematerra P., Fontana F., 1996 - Monitoring of Webbing Clothes Moth, Tineola bisselliella (Hummel), by sex pheromone. Anz. Schädlingskde. Pflanzenschutz Umweltschutz, 69: 119121.

WeidNER H., 1958 - Die Entstehung der Hausinsekten. Zeitschrift für angewandte Entomologie, 42 (4): 429-447.

Weidner H., 1970 - Die Kleidermotte, Tineola bisselliella (Hummel, 1823). Der praktische Schädlingsbekämpfer, 22(5): 70-76.

ZeLLer P.C., 1852 - Die Schaben mit langen Kieferntastern. Linnaea Entomologica, 6: 81-197.

Bianca Krüger-Carstensen, BAM, Unter den Eichen 87, 12205 Berlin, Germany.

E-mail: bianca.krueger-carstensen@bam.de

Rudy Plarre, BAM, Unter den Eichen 87, 12205 Berlin, Germany.

E-mail: ruediger.plarre@bam.de 